\title{
Políticas educacionais e redes de influência: QUE EDUCAÇÃO QUEREM OS REFORMADORES?
}

\section{Educational policies and influence networks: what kind of education do reformers want?}

\begin{abstract}
RESUMO No presente artigo, pretende-se discutir as concepções de educação expressas pelos reformadores empresariais da educação e suas formas de influência na escrita do texto da política educacional brasileira. Essa intensificação da lógica do mercado na educação é permeada pelos conceitos de responsabilização, privatização e performatividade (BALL, 2005). Utiliza-se a abordagem do Ciclo de Políticas (BOWE et al., 1992) e análise de documentos estratégicos de representantes do setor, como a Confederação Nacional da Indústria e o movimento Todos pela Educação. A partir da pesquisa, é possível afirmar que a avaliação em larga escala vem sendo empregada para fortalecer conceitos relacionados às concepções de educação dos reformadores na prática escolar e na opinião pública.
\end{abstract}

Palavras-chave: Redes de influÊnCia. Política educacional. AVALIAÇÃO EXTERNA. REFORMADORES EMPRESARIAIS DA EDUCAÇÃO.

ABSTRACT The intention of this article is to discuss the concepts of education sought out by the corporate reformers and their forms of influence in the writing of the legislation of the Brazilian educational policy. This intensifying of the market logic in education is permeated by the concepts of accountability, privatization and performativity (BALL, 2005). The article uses the policy cycle approach (BOWE et al., 1992) and analysis of strategic documents of industry representatives, such as the National Confederation of Industry and the All for Education movement. From the research, it is possible to affirm that the large-scale evaluation has been used to strengthen notions related to the education reformer's conceptions in school practice and public opinion.

KEY-WORDS: INFLUENCE NETWORKS. EDUCATIONAL POLICIES. LARGE-SCALE EVALUATION. CORPORATE REFORMERS.

\section{INTRODUÇÃO}

este artigo, pretende-se discutir as concepções de educação expressas pelos reformadores empresariais da educação ${ }^{1}$ e suas formas de influência na escrita do texto da política educacional brasileira. Em especial, nas políticas de avaliação em larga escala.

1 No Brasil, o termo foi cunhado por Freitas (2012) e será melhor explicado no decorrer do texto.

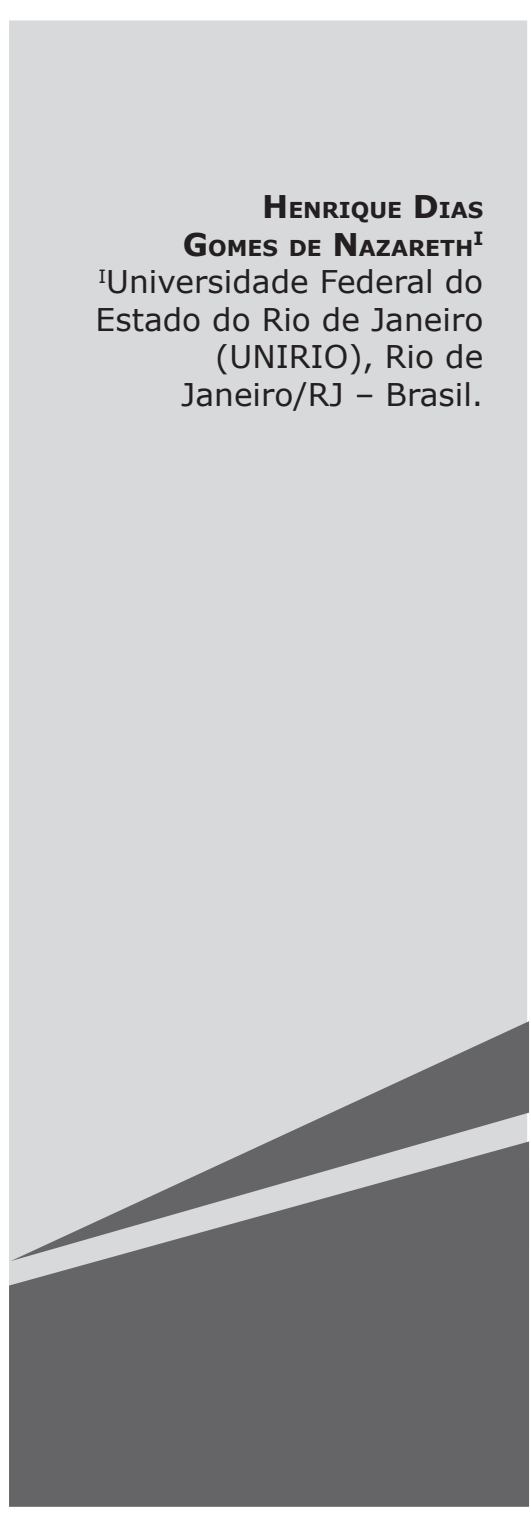


Utiliza-se a abordagem do Ciclo de Políticas ${ }^{2}$ e análise de documentos estratégicos de dois representantes dos reformadores: o movimento Todos pela Educação (TPE) e a Confederação Nacional da Indústria (CNI). A partir da pesquisa, é possível afirmar que a avaliação em larga escala vem sendo empregada para fortalecer conceitos relacionados às concepções de educação dos reformadores na prática escolar e na opinião pública.

A educação pública brasileira, nas últimas décadas, passa por um momento de intensificação da lógica mercadológica, isto é, há um movimento de introdução de conceitos característicos da iniciativa privada empresarial que se apresentam no campo de disputa das políticas educacionais. A importação ${ }^{3}$ de políticas estrangeiras e a participação ativa de fundações privadas e movimentos financiados por empresários podem ser apontados como alguns dos responsáveis por influenciar a pauta da política educacional. Freitas (2012) explica que:

Esta "nova abordagem" para as políticas públicas de educação está sendo construída em torno dos conceitos de responsabilização, meritocracia e privatização. Estes constituem um bloco interligado onde a responsabilização pelos resultados (leia-se: aumento da média em testes nacionais e internacionais) é legitimada pela meritocracia (distinções ou sanções fornecidas com base no mérito de ter aumentado ou não as médias) com a finalidade de desenvolver novas formas de privatização do público (o qual é desmoralizado pela meritocracia das médias mais altas), visando a constituição de um "espaço" que se firma progressivamente como

BOWE et al., 1992.

3 É relevante destacar que essa afirmação não ignora o movimento de recontextualização das políticas localmente. Considera-se que quando políticas são importadas também se transformam na relação com os contextos e demandas locais. "público não estatal” em contraposição ao "público estatal”. ${ }^{4}$

A avaliação em larga escala desempenha papel essencial nesse contexto. Introduzindo os conceitos supracitados (responsabilização, meritocracia e privatização), exames de desempenho estão cada vez mais presentes no calendário escolar. Não só os exames em si, outros instrumentos atrelados a eles como índices e premiações das escolas pelos resultados promovem a performatividade nas instituições escolares, caracterizada por Ball (2005) como:

A performatividade é uma tecnologia, uma cultura e um método de regulamentação que emprega julgamentos, comparações e demonstrações como meios de controle, atrito e mudança. Os desempenhos de sujeitos individuais ou de organizações servem de parâmetros de produtividade ou de resultado, ou servem ainda como demonstrações de "qualidade" ou "momentos" de promoção ou inspeção. ${ }^{5}$

Serão discutidas, no desenvolvimento deste artigo, algumas formas como os reformadores têm defendido a introdução de políticas educacionais identificadas com a performatividade, meritocracia e responsabilização.

Para isso, faz-se uso do referencial teórico analítico conhecido como "abordagem do ciclo de políticas" elaborado por Stephen J. Ball e Richard Bowe. Para a compreensão da formação do discurso político e interpretação dele na prática, é proposto um "ciclo contínuo constituído por três contextos principais: o contexto de influência, o contexto da produção de texto e o contexto da prática". ${ }^{6}$ Os contextos não são fragmentados, autônomos ou isolados, estão imbricados. Não há ordem sequencial ou temporal. "Cada um desses

\footnotetext{
FREITAS, 2012, p. 346.

BALL, 2005, p. 543.

MAINARDES, 2006, p. 50.
} 
contextos apresenta arenas, lugares e grupos de interesse e cada um deles envolve disputas e embates."

O contexto de influência é "onde normalmente as políticas públicas são iniciadas e os discursos políticos são construídos. É nesse contexto que os grupos de interesse disputam para influenciar a definição das finalidades sociais da educação e do que significa ser educado". ${ }^{8}$

O contexto da produção do texto político diferencia-se do primeiro, por estar relacionado à linguagem do interesse público mais geral. "Os textos políticos, portanto, representam a política. Essas representações podem tomar várias formas: textos legais oficiais e textos políticos, comentários formais ou informais sobre os textos oficiais, pronunciamentos oficiais, vídeos etc." 9

No terceiro contexto, o da prática, o texto da política é interpretado. Ball ${ }^{10}$ nega qualquer possibilidade de implementação absoluta da política, ela é sempre recontextualizada e encenada na prática, onde pode se transformar na relação com os sujeitos.

Para fins de análise, este artigo está focado no contexto de influências. Entretanto, não há pretensão de mapear todo o contexto de influências das políticas de avaliação em larga escala ou as ações dos reformadores empresariais da educação. ${ }^{11} \mathrm{O}$ que se pretende aqui é, por meio da análise de documentos e auxílio de outras pesquisas, discutir algumas concepções de educação que se encontram no discurso dos reformadores e compreender as formas como eles exercem influência na elaboração das políticas.

As redes municipais de educação no país estão sendo influenciadas pela atuação dos reformadores da educação, como no caso específico da Rede Municipal do Rio de Janeiro. Por isso, algumas informações sobre essa rede de ensino serão apresentadas com a finalidade de ilustrar as questões debatidas.

BOWE et al. apud MAINARDES, 2006, p. 50.

MAINARDES, 2006, p. 51.

Ibid., p. 52.

BALL apud MAINARDES E MARCONDES, 2009.

FREITAS, 2012.

\section{REDES DE INFLUÊNCIA E REFORMADORES EMPRESARIAIS DA EDUCAÇÃO}

Freitas (2012) examina a ação dos reformadores empresariais da educação, os quais configuram-se em uma coalizão composta por políticos, veículos de mídia, pesquisadores, empresários e organizações sem fins lucrativos financiadas pela iniciativa privada.

"Corporate reformers" - assim são chamados os reformadores empresariais da educação nos Estados Unidos, em termo criado pela pesquisadora americana Diane Ravitch (2011b). Ele reflete uma coalizão entre políticos, mídia, empresários, empresas educacionais, institutos e fundações privadas e pesquisadores alinhados com a ideia de que o modo de organizar da iniciativa privada é uma proposta mais adequada para "consertar” a educação americana, do que as propostas feitas pelos educadores profissionais. Naquele país, a disputa de agenda entre os educadores profissionais e os reformadores empresariais da educação vem de longa data. ${ }^{12}$

Percebe-se que no âmbito da regulamentação há um avanço dos reformadores empresariais que será demonstrado no desenvolvimento deste artigo. Os reformadores organizam-se em redes sociais, definidas por Shiroma (2011) como "um conjunto de pessoas e/ou organizações que se agregam com interesse comum, contribuem para a produção e disseminação de informações, criam canais de comunicação e estimulam a participação da sociedade".

A atuação de redes sociais no contexto de influências é sugerida por agências multilaterais como Banco Mundial (BM) e Banco Interamericano de Desenvolvimento (BID), informação que a autora demonstra, ao citar o documento publicado pelo BM, em 2006,

12 FREITAS, 2012, p. 380.

13 SHIROMA, 2011, p. 18. 
Education Sector Strategy Update (ESSU): achieving education for all, broadening our perspective, maximizing our effectiveness.

No documento de 2006, em que torna públicas as atualizações para o Setor da Educação, destaca-se o uso estratégico das redes sociais, anunciando que: 'O Banco se articulará com redes nacionais e regionais de pesquisa para construir sentimento de pertença e foco nos resultados e sustentá-los localmente'. ${ }^{14}$

Um exemplo de que essa recomendação foi colocada em prática é a criação e atuação do Movimento Todos Pela Educação (TPE). Fundado em 2006, ano de publicação do documento supracitado, o TPE é descrito como um movimento da sociedade civil brasileira, cuja missão é contribuir para que até 2022, ano do bicentenário da Independência do Brasil, o país assegure a todas as crianças e jovens o direito à Educação Básica de qualidade. O movimento é mantido por instituições como Gerdau, Santander, Instituto Unibanco, além de ter parcerias com entidades como Instituto Ayrton Senna, Fundação Victor Civita e BID. ${ }^{15}$

A agenda do TPE fundamenta-se nas seguintes metas: Toda criança e jovem de 4 a 17 anos de idade na escola; Toda criança plenamente alfabetizada até os 8 anos de idade; Todo aluno com aprendizado adequado à sua série; Todo jovem de 19 anos de idade com o Ensino Médio concluído; Investimento em Educação ampliado e bem gerido.

O TPE configura-se como uma das formas de atuação dos reformadores com maior influência a nível nacional. O movimento, apesar de fundado em 2006, já conseguiu que suas metas virassem decreto presidencial em 2007. O Plano de Metas Compromisso Todos Pela Educação foi incorporado no Decreto $n^{\circ}$. 6.094, de 24 de abril de 2007, que dispõe:

14 Ibid., p. 18.

15 TODOS PELA EDUCAÇÃO, 2013.
Sobre a implementação do Plano de Metas Compromisso Todos pela Educação, pela União Federal, em regime de colaboração com Municípios, Distrito Federal e Estados, e a participação das famílias e da comunidade, mediante programas e ações de assistência técnica e financeira, visando a mobilização social pela melhoria da qualidade da educação básica. ${ }^{16}$

No Decreto supracitado, a segunda meta do TPE "Toda criança plenamente alfabetizada até os oito anos" também aparece:
Art. $2^{\circ}$ A participação da União no Compromisso será pautada pela realização direta, quando couber, ou, nos demais casos, pelo incen- tivo e apoio à implementação, por Municípios, Distrito Federal, Es- tados e respectivos sistemas de ensino, das seguintes diretrizes: (...)
II - alfabetizar as crianças até, no máximo, os oito anos de idade, afe- rindo os resultados por exame peri- ódico específico. ${ }^{17}$

Além dessa, o Decreto apresenta mais 27 diretrizes, entre elas estão: incentivo à educação de pessoas com necessidades educativas especiais em classes comuns; ampliação da educação em tempo integral; promoção da educação infantil; matrícula de alunos em escolas próximas às suas residências. Também é possível encontrar diretrizes mais diretamente relacionadas ao projeto dos reformadores para a educação, tais como: plano de carreira privilegiando o mérito; divulgação do Índice de Desenvolvimento da Educação Básica (IDEB) nas escolas e comunidades; e criação de comitês locais de acompanhamento das metas do IDEB com representantes das associações de

16 BRASIL, 2007, p. 5.

17 Ibid., p. 5. 
empresários, trabalhadores, sociedade civil, Ministério Público, Conselho Tutelar e dirigentes do sistema educacional público.

A segunda meta do TPE também serviu como base para o Pacto Nacional pela Alfabetização na Idade Certa (PNAIC).$^{18}$ Ela aparece como Meta 5 do projeto de lei que trata sobre o Plano Nacional de Educação ao determinar a necessidade de "alfabetizar todas as crianças até, no máximo, oito anos de idade". No âmbito municipal, a prefeitura do Rio de Janeiro apresenta a meta "Garantir que, pelo menos, 95\% das crianças com sete anos de idade ao final do ano de 2016 estejam alfabetizadas". ${ }^{19}$

Evangelista e Leher (2012) chamam a atenção para a atuação do TPE nos governos:

Embora o Todos Pela Educação seja formalmente uma iniciativa de classe, autônoma em relação ao Estado e ao governo, somente pode cumprir seus objetivos operando por meio dos governos e, por isso, vem construindo, em seus conselhos, articulações com os novos gestores da educação pública no Brasil, tanto no MEC, como nas secretarias de educação. ${ }^{20}$

Os representantes dos reformadores transitam entre cargos no MEC, secretarias de educação, conselhos de educação e instituições financiadas pelo setor industrial e bancário, além de terem espaço nas grandes mídias.

Claudia Costin, Secretária de Educação do Município do Rio de Janeiro de 2009 até 2014, é um exemplo da questão supracitada. No setor público, foi Ministra da Administração Federal e Reforma do Estado e Secretária de Cultura do Estado de São Paulo; no setor privado, atuou como vice-presidente da Fundação Victor Civita; além de atuar no BM como Gerente de Políticas Públicas para a América Latina e Diretora Global de Educação. Durante sua gestão na Secretaria de Educação do

18 BRASIL, 2012.

19 RIO DE JANEIRO, 2013, p. 63.

20 EVANGELISTA; LEHER, 2012, p. 8.
Rio de Janeiro, era chamada constantemente para opinar e divulgar ações promovidas por sua secretaria nos jornais de grande circulação da cidade.

O campo educacional ${ }^{21}$ é amplo, diverso e composto por regiões de fronteiras entre outros campos que disputam o objeto "qualidade da educação". Alguns desses campos são: político, terceiro setor, ${ }^{22}$ sindical, pesquisa educacional e o jornalístico.

Desse modo, o campo educacional é um espaço amplo e heterogêneo, com regiões de fronteira que cruzam com outros campos mediante atores com trajetórias próprias e poder simbólico expresso em habitus ${ }^{23}$ incorporados, condizente com sua pertença a um determinado campo (intelectuais, professores, dirigentes sindicais, políticos etc.). Esses campos são interdependentes e cruzam as fronteiras do campo educacional à medida que seus atores reivindicam uma melhor concepção de educação, utilizando-se de estratégias de luta em que a visibilidade de seu capital específico permite ocupar posições de liderança, consubstanciada em consenso pedagógico. ${ }^{24}$

21 Adota-se o conceito de campo de BOURDIEU (2010; 2004), que se classifica como um universo social que tem leis e regras de funcionamento mais ou menos autônomas em relação ao contexto. O autor se refere ao campo como microcosmos relativamente autônomos, já que apesar de não escapar totalmente às imposições do macrocosmo, gozam de certo grau de autonomia e de regras de funcionamento próprias.

22 Para RUGGERI (2011) "terceiro setor é um espaço relacional na sociedade com uma finalidade específica, a proteção social. É uma área intermediária em não claramente definida do espaço público na sociedade civil, (...) misturam recursos e lógicas de setores diferentes, com papéis políticos e econômicos de igual importância" (p. 12).

23 "Bourdieu corresponde o que acontece em um campo ao habitus dos agentes que se inter-relacionam em seu interior" funcionando como "[...] um princípio que organiza, dá sentido e conforma as práticas dos agentes no interior dos campos" (FERNANDES, 2003, p. 96). O habitus é o princípio que dá sentido para as ações dos sujeitos dentro do campo e, por isso, tem a ver com as práticas tanto individuais como coletivas.

24 RICARDO FILHO, 2005, p. 36. 
Ricardo Filho (2005) explica que é justamente na intersecção entre vários campos que "as lutas pelo controle da prescrição de uma boa escola são mais bem explicadas". ${ }^{25}$ Em outras palavras, a disputa do objeto "educação de qualidade" (ou boa escola) trava-se no campo educacional, onde adquirem maior legitimidade aqueles agentes que conseguem transitar nas fronteiras dos diferentes campos.

$O$ estudo do autor demonstra que mesmo pessoas sem tanto prestígio sob o habitus do campo universitário (ou da pesquisa educacional) atuam: no campo político (assumindo secretarias de educação); no terceiro setor (em movimentos como o “Todos pela Educação"); no espaço jornalístico (conquistando legitimidade no campo educacional) e são evocados como autoridades na formulação das políticas.

Para ele, esse movimento vai criando uma rede de legitimidade que ajuda a explicar o conceito "boa escola" ou "escola de qualidade" na imprensa. O tema marcadamente polissêmico no campo da pesquisa educacional se apresenta como um consenso nas mídias. ${ }^{26}$ Dessa forma, as redes sociais para educação e seus representantes que transitam entre diversos campos demonstram grande capacidade de mobilização e articulação.

Em 2011, o TPE, em parceria com o BID, promoveu em Brasília o Encontro Latino-Americano de Organizações da Sociedade Civil pela Educação, no qual participaram treze organizações da América Latina, além de representantes do BID e o Ministro da Educação Fernando Haddad. Nesse encontro, foi lançada a Rede Latino-americana de Organizações da Sociedade Civil para a Educação (REDUCA). A REDUCA é formada por organizações sociais de treze países, a saber: Proyecto EducAR 2050 (Argentina); Todos Pela Educação (Brasil); Fundación Educación (Chile); Fundación Empresarios por La Educación (Colômbia); Grupo FARO (Equador); Fundación Empresarial para el Desarrollo Educativo - Fepade (El Salvador);

5 Ibid., p. 37.

26 É possível encontrar mais informações sobre o assunto em FERNANDES; NAZARETH, 2011.
Empresarios por La Educación (Guatemala); Fundación Educativa Ricardo Ernesto Maduro Andreu - Ferema (Honduras); Mexicanos Primero (México); Unidos por La Educación (Panamá); Juntos por la Educación (Paraguai); Asociación Empresarios por la Educación (Peru); EDUCA (República Dominicana).

Nota-se a interessante semelhança entre os nomes das organizações. Algumas evidenciam na nomenclatura a representatividade dos interesses dos empresários; já outras, tentam passar a ideia de que representam toda sociedade civil, como o próprio TPE e o Juntos por La Educación do Paraguai. Observa-se que os últimos também são compostos por representantes da indústria e do setor bancário.

A REDUCA foi criada com os seguintes propósitos: "1) trabalhar em conjunto para a garantia do direito à educação de qualidade para toda criança e jovem; 2) trocar conhecimento e aprender coletivamente; 3) ter uma voz coletiva no nível regional". ${ }^{27}$

Os propósitos são genéricos e por si só não permitem compreender as concepções de educação da REDUCA; todavia, as metas comuns da rede para 2024 são: que os estudantes obtenham trajetórias completas de 12 anos de escolaridade e que os países da América Latina atinjam a média da Organização para a Cooperação e Desenvolvimento Econômico (OCDE) no Programa Internacional de Avaliação de Estudantes (PISA). Mais uma vez, a avaliação externa aparece como instrumento estratégico.

Em um momento posterior ao lançamento da REDUCA, ficou a cargo de três organizações dar continuidade às propostas comuns para a rede, como explica Martins (2013):

A elaboração de uma plataforma de dados sobre a educação em toda América Latina, à cargo do grupo Mexicanos Primero (México); a elaboração de uma plataforma de informações e notícias vinculadas às organizações da rede, sob res-

27 MARTINS, 2013, p. 2. 
ponsabilidade do grupo Todos pela Educação (Brasil); e a construção de um banco de "boas práticas" que possam ser transladadas de um país para o outro, tarefa à cargo do grupo Educación 2020 (Chile). ${ }^{28}$

Com essa ação, a rede busca aumentar seu grau de influência na América Latina, por meio da integração entre as organizações. Questão que fica em evidência na missão divulgada no site oficial da REDUCA.

Ser uma rede de aprendizagem colaborativa para tornar nossas intervenções mais eficazes na busca de uma educação inclusiva e de qualidade em cada um dos nossos países, e para a construção de uma voz regional coletiva de apoio, mobilização e incidência sobre as políticas públicas de educação que promovem a visão compartilhada. ${ }^{29}$

A ideia de intervir cada vez mais nas políticas públicas de educação é declarada, pois assim essas organizações apresentam-se como defensoras da qualidade na educação. A questão é que a qualidade almejada por elas está relacionada à ideia de avaliação para controle e padronização curricular. Freitas (2012) disserta sobre esse movimento de avanço da lógica reformadora na política educacional:

Os educadores profissionais acompanham este movimento com apreensão, pelo fato de que a educação é um fenômeno social mais amplo e que, do ponto de vista de seus compromissos formativos com a juventude, não pode ter na economia seu único determinante. Ao ser aprisionada na lógica empresarial, a educação perde sua dimensão de um bem público mais amplo, cujos horizontes devem ser um projeto de nação e não apenas a expressão de uma demanda de um dos seus

28 Ibid., p. 3.

29 REDUCA, 2015, p. 1. atores, os empresários, por mais importante que estes possam ser..$^{30}$

Observa-se que as políticas de avaliação externas têm sido um pilar da proposta educacional dos reformadores. Mais do que avaliar redes de ensino para subsidiar a formulação de políticas e ações de melhoria, os indicadores de resultados são ferramentas estratégicas desse discurso. Lima e Gandin (2012) explicam que no Brasil as avaliações foram responsáveis por introduzir a noção de quase-mercado na educação, que é o "processo no qual valores de mercado são adotados nas instituições públicas". ${ }^{31}$

Por tudo isso, afirma-se que a avaliação tem sido a mola mestra das reformas educacionais. Ou "em outras palavras, a avaliação está no centro das reformas, no foco das disputas que se travam no campo da educação e se referem a disputas mais amplas pela construção de tipos distintos de sociedade". ${ }^{32}$

No bojo das propostas reformistas está a pressão pela redução da carga horária das disciplinas que não são avaliadas nos testes de larga escala. Esse estreitamento curricular é definido por Gesqui (2015) como "a opção feita pelas escolas por ampliar deliberadamente o número de atividades relacionadas aos componentes curriculares presentes nas avaliações externas e reduzir, também deliberadamente as atividades relacionadas aos demais componentes curriculares". ${ }^{33}$

A questão também pode ser observada ao olhar para o enfoque demasiado que tem sido atribuído às disciplinas de língua portuguesa e matemática na matriz curricular da rede de educação do município do Rio de Janeiro.

Esse município orienta o professor da Casa de Alfabetização $\left(1^{\circ}\right.$. ao $3^{\circ}$. do ensino fundamental) a trabalhar língua portuguesa e matemática, além de atribuir alguns tempos semanais para arte, língua estrangeira e sala de leitura, como pode ser observado na Tabela 1.

FREITAS, 2012, p. 345.

LIMA; GANDIN, 2012, p. 78.

DIAS SOBRINHO, 2003, p. 95.

GESQUI, 2015, p. 234. 
Tabela 1 - Matriz curricular para o ensino fundamental de tempo parcial das escolas municipais do Rio de Janeiro

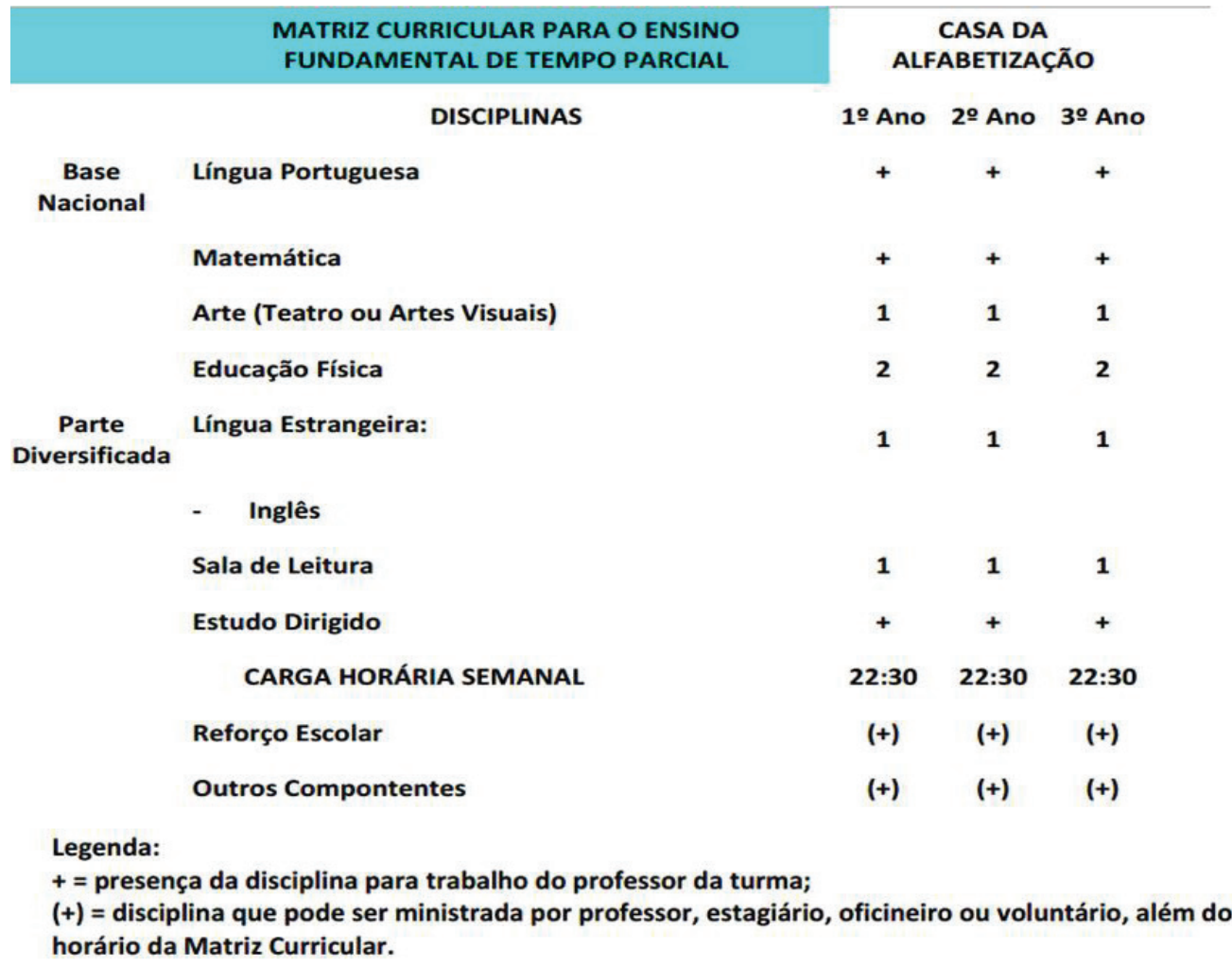

Fonte: Resolução SME Nº 1.178/2012.

Essa matriz omite, nos anos iniciais do ensino fundamental, disciplinas como história, geografia, ciências e educação artística que na matriz curricular de $2004^{34}$ estavam presentes. Esse estreitamento curricular é característico do projeto dos reformadores para a educação pública. Tem relação com a concepção de qualidade da educação vinculada somente ao desempenho em avaliações externas, na medida em que prioriza as disciplinas avaliadas nos testes externos.

A questão também é reforçada pela elaboração e divulgação dos descritores. ${ }^{35}$ Nesse contexto, a Secretaria de Educação do Rio de Janeiro só divulgava os descritores das disci-

34 Regulamentada pela Resolução SME Nº. 2.640/2004.

35 "Os descritores: (1) indicam habilidades gerais que se esperam dos alunos; (2) constituem a referência para seleção dos itens que devem compor uma prova de avaliação" (BRASIL, 2008, p. 18). plinas testadas, evidenciando a relação direta com as provas, e o estreitamento curricular por meio das pressões das avaliações externas. Oliveira (2012) afirma que:

A ligação dos Descritores com a ava-
liação/teste é direta, pois é para ela
que são estabelecidos. A definição
de Descritores para produção de
testes possibilita uma visão geral
das habilidades que serão avaliadas,
tanto por parte de quem produz o
teste, quanto daqueles que o aplica-
rão ou estudarão seus resultados. ${ }^{36}$

A adaptação do currículo frente às avaliações externas se apresenta como um pressuposto da proposta dos reformadores, pois

36 OLIVEIRA, 2012, p. 81. 
vincula os índices gerados pelos resultados das provas a um conceito de qualidade da educação.

Os reformadores utilizam o termo educação de qualidade como ferramenta retórica. Ball (2006) disserta sobre isso quando argumenta que a educação está sujeita à retórica de aperfeiçoamento dessa chamada revolução da qualidade:

Tem sido uma característica-chave das reformas governamentais no Reino Unido (e em vários outros lugares) desde o início dos anos 1980. [...] Muito da parafernália de qualidade é tomada de empréstimo do setor privado - o setor público, foi defendido [segundo essa retórica], se beneficiaria da exposição às forças do mercado, aos modelos comerciais de gerenciamento e de aperfeiçoamento da qualidade. ${ }^{37}$

Assim, fica evidente a importância da retórica da qualidade na imposição do projeto dos reformadores para a educação pública que se referenciam na lógica do mercado e buscam a criação de um "novo ambiente moral" no setor público. Ambiente no qual, valores como competitividade, empreendedorismo e flexibilidade se impõem no lugar de estabilidade, cooperação e justiça social. Ao contrário dessa retórica da qualidade, este trabalho compreende que a qualidade da educação é um fenômeno complexo que possui determinações intraescolares (currículo, formação docente, gestão escolar etc.) e extraescolares (condições de vida da população, capital econômico e cultural das famílias dos alunos, entre outros). ${ }^{38}$

Os autores demonstram as limitações de algumas visões de educação de qualidade que tratam com simplismo o fenômeno:

Nesse caso, encontram-se as que priorizam: desempenho satisfatório em exames nacionais; domínio

37 BALL, 2006, p. 14.

38 MOREIRA; KRAMER, 2007. de conhecimentos, habilidades e competências que se estabeleçam previamente; emprego de tecnologias avançadas; supervalorização da competitividade e da produtividade; novos métodos de gerenciamento de sistemas e instituições educacionais; procedimentos integrados e flexíveis no trabalho pedagógico. 39

Não se descarta a importância de alguns desses aspectos dentro da ótica da qualidade da educação como fenômeno complexo; porém, a crítica se fundamenta quando:

A noção de qualidade se funda ape-
nas em pressupostos técnicos e se
distancia dos juízos de valor, do
compromisso com a justiça social,
bem como das ações e dos interes-
ses dos sujeitos que concretamente
a define e adota. ${ }^{40}$

Nas metas estabelecidas pelos reformadores e regulamentadas na política educacional, observa-se que a qualidade é sempre medida por índices que consideram apenas o desempenho de alunos e taxas de matrículas. Até as metas referentes à alfabetização estão atreladas ao desempenho dos alunos em provas, na quais se tentam mensurar os índices de apreensão da língua portuguesa escrita e da matemática.

Sendo assim, Moreira e Kramer (2007) concluem argumentando que:

O conceito de qualidade é historicamente produzido, não cabendo, portanto, pensá-lo em termos absolutos. Pressupõe uma análise processual, uma dinâmica, assim como a recuperação do específico e o respeito às condições conjunturais. Trata-se, em síntese, de concepção formulada com base em um arbitrá-

39 Ibid., p. 1.043 .
$40 \quad$ Ibid., p. 1.043 . 
rio sociocultural e norteada por demandas distintas e mutáveis. ${ }^{41}$

Ao reconhecer a base arbitrária sob a qual os conceitos de qualidade têm sido constituídos, pode-se problematizar a questão e propor uma ótica mais coerente com recentes pesquisas em avaliação e currículo. Portanto, levanta-se a bandeira da qualidade identificada com o argumento das escolas como:

Formas sociais que ampliam as capacidades humanas, a fim de habilitar as pessoas a intervir na formação de suas próprias subjetividades e a serem capazes de exercer poder com vistas a transformar as condições ideológicas e materiais de dominação em práticas que promovam o fortalecimento do poder social e demonstrem as possibilidades da democracia. ${ }^{42}$

Na contramão, o documento "Mapa Estratégico da Indústria 2013-2022"43 representa a visão de qualidade da indústria brasileira, seus objetivos e metas tendo como referência o ano 2022, marco dos 200 anos de independência formal. Apesar de apontar a educação como fator-chave de competitividade da indústria, essa declaração escrita configura-se como uma síntese da posição de 500 representantes empresariais, que foi construída sem a busca da contribuição dos educadores profissionais.

A indústria brasileira apresenta a sua visão para o país. O Mapa Estratégico da Indústria 2013-2022 representa um esforço, de mais de 500 representantes empresariais, em definir as ações necessárias para fazer o Brasil crescer mais e melhor, e refletir sobre os problemas que impedem esse crescimento. ${ }^{44}$

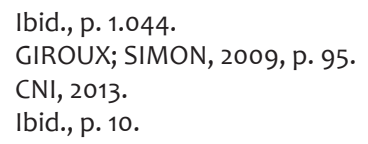

A importância da educação para esses representantes empresariais é ressaltada em várias partes do documento já referido. A educação é apontada como um problema no cenário atual e como possibilidade de diferencial competitivo. Quando se trata do assunto, é possível perceber um tom apelativo, não há base em pesquisa que justifique as metas sugeridas. No trecho, a seguir, afirma que o futuro da indústria é contingente; pois, "Depende da nossa capacidade de atuar sobre os problemas, do desenvolvimento de novas competências em educação e inovação e da adaptação às condições da economia global". 45

Para esses representantes do empresariado, "Equipes educadas e engenheiros bem formados utilizam melhor os equipamentos, criam soluções para os problemas do dia a dia, adaptam processos e produtos e desenvolvem e implementam inovações". ${ }^{46}$ Dentro dessa perspectiva, a necessidade de mão de obra flexível e adaptável às demandas e às dinâmicas das novas tecnologias fica evidente.

O documento apresenta um quadro de fracasso da educação básica, ou de baixa qualidade da educação. Esse argumento fundamenta-se na comparação da nota média do Brasil no PISA e na posição ocupada no comparativo internacional. Nota-se a ausência de uma explicação sobre como desempenhos melhores em provas de leitura, matemática e ciências transformam alunos em trabalhadores que criam soluções para problemas do dia a dia no trabalho.

Talvez por isso o documento separa os temas prioritários da educação em três: educação básica; educação profissional; e formação de engenheiros e tecnólogos. Na educação básica, o objetivo prioritário é aumentar a qualidade; na educação profissional, o objetivo é ampliar a oferta e melhorar a qualidade; e, para a formação de engenheiros e tecnólogos, somente almeja-se a ampliação da oferta.

Pode-se supor que a melhoria do desempenho na educação básica não necessariamente está relacionada à formação de melho-

45 Ibid., p. 10.

46 Ibid., p. 28. 
res engenheiros ou tecnólogos, até porque, a qualidade da formação desses profissionais não é questionada. De acordo com o documento discutido, o problema da educação básica é a ineficiência:

Os resultados em termos de qualidade da educação não são condizentes com o volume de recursos investidos na área. $\mathrm{O}$ investimento em educação no Brasil representa $5,7 \%$ do PIB, percentual próximo ao de países como Holanda, França e Estados Unidos. Na última avaliação do PISA (Programa Internacional de Avaliação de Alunos, realizado pela OCDE), em 2009, o Brasil ocupou a $54^{\mathrm{a}}$ colocação, enquanto a Holanda ficou em $9^{\circ}$ lugar, a França em $25^{\circ}$ e os EUA em $26^{\circ}$. A situação é pior quando o conteúdo avaliado é matemática, que coloca os alunos brasileiros na $57^{\mathrm{a}}$ posição. ${ }^{47}$

Dessa maneira, a meta proposta é passar da $54^{a}$ posição do ranking de 2009 para a $43^{\mathrm{a}}$ posição no ano 2021, aumentando a nota média de 401, em 2009, para 480, em 2021. O documento destaca que 480 é uma média próxima da Espanha, em 2009. As estratégias propostas são as seguintes:

- Fomentar a qualificação dos professores da educação básica e dos diretores de escolas públicas;

- Desenvolver e disponibilizar práticas pedagógicas inovadoras adequadas às escolas públicas;

- Estimular a ampliação e o cumprimento da jornada escolar;

- Desenvolver estratégias para fortalecer o ensino de português, matemática e ciências na educação básica;

- Promover a adoção de diretrizes curriculares voltadas para o mundo do trabalho;

- Fomentar a articulação de conteúdos técnicos com conteúdos de educação básica;

47 Ibid., p. 30.
- Fomentar e desenvolver ações para a aproximação da família da realidade das escolas. ${ }^{48}$

Para a CNI, a escola precisa apresentar desempenhos melhores nas avaliações externas, equiparando-se com países que investem o mesmo percentual do PIB que o Brasil. Além disso, acredita que as escolas devem preparar melhor seus alunos para o mercado do trabaIho. Assim, se teria maior competitividade e menor investimento em treinamento dos trabalhadores.

Do ponto de vista pedagógico, cabe um questionamento: será que os estudantes treinados para realizar exames serão mão de obra qualificada? O que se percebe é a existência de problemas na análise e execução das ações propaladas pela política, pois partem de uma premissa equivocada do que seria formar bem para a eficiência no mercado de trabalho.

\section{O PAPEL DA AVALIAÇÃO EXTERNA NO DIS- CURSO REFORMISTA}

Os reformadores empresariais da educação acreditam que o Estado onera excessivamente as empresas e não provê a escolarização que almejam, como pode ser observado no documento:

A ineficiência do Estado gera dois efeitos principais sobre a competitividade: extrai recursos das empresas superiores ao necessário, reduzindo a sua eficiência, e provê, em quantidade e qualidade inadequadas, bens públicos que geram externalidades positivas, como educação, infraestrutura e segurança pública. O Estado brasileiro gasta muito com custeio. $\mathrm{O}$ aumento da eficiência do Estado passa pela maior alocação dos recursos em investimento. É preciso melhorar a composição do gasto público com maior participação dos investimen- 
tos. Para isso, faz-se necessário melhorar a capacidade de o Estado planejar e executar suas políticas e investimentos. ${ }^{49}$

Os reformadores afirmam que a educação pública sofre uma crise de ineficiência. $O$ argumento que sustenta essa crise favorece a adoção das medidas propostas pelos próprios reformadores. Ravitch (2013) apresenta o discurso dos reformadores nos Estados Unidos da América da seguinte forma:

Nossos alunos não estão aprendendo o suficiente. As escolas públicas são ruins e estão ficando pior. Estamos perdendo para outros países com os resultados dos testes mais elevados. Nossas escolas públicas em decadência ameaçam não só o desempenho da nossa economia, mas a nossa segurança nacional, a nossa própria sobrevivência como nação. Essa crise é tão profunda que meias medidas e ajustes não serão suficientes. Escolas devem ser fechadas e um grande número de professores demitidos. Quem duvida disso não conhece as dimensões da crise ou tem interesse em defender o status quo..$^{0}$

Eles sustentam o argumento de que para melhorar a qualidade é preciso melhorar o desempenho, e para melhorar o desempenho é necessário estabelecer metas, comprar "soluções" educacionais, fazer mais provas e premiar aqueles que conseguirem alcançar as metas.

No caso do Brasil, a comparação entre o desempenho com outros países (por intermédio do PISA), entre Estados e municípios e a classificação das escolas fortalecem o argumento da crise. Isso pode ser visto na reportagem "Na série B da Educação", publicada no jornal O Globo em 18/05/2009. O texto retrata

49 CNI, 2013, p. 42.

50 RAVITCH, 2013, p. 3. a mudança na forma de avaliação do PISA que na edição do ano de 2009 teve questões consideradas mais fáceis, com o intuito de identificar diferenças entre o desempenho de alunos com baixo rendimento. Na referida reportagem, acredita-se ser possível medir a qualidade do ensino pelo desempenho dos estudantes em grandes avaliações padronizadas. Nela, não são consideradas as especificidades do exame, como a participação somente de alunos de 15 anos, sem levar em conta seu grau de escolaridade, e a abordagem de ciências, matemática e português. Como fica explícito no trecho a seguir:

A nota alcançada pelos alunos brasileiros sempre ficou abaixo da média geral. O número de países que participam varia em cada edição do exame, um dos mais importantes para medir a qualidade do ensino. São avaliados estudantes de 15 anos de idade, independentemente da série que cursam..$^{51}$

O texto continua reforçando a ideia de que o exame é capaz de medir o aprendizado, ou seja, parte da perspectiva de que o baixo desempenho no exame significa pouco aprendizado e por isso pouca qualidade do sistema de ensino.

O coordenador-geral do Pisa na OCDE, Andreas Schleicher, considera surpreendente uma parcela significativa dos estudantes de 15 anos aprender tão pouco, apesar de frequentar a escola por quase uma década ou mais. Segundo ele, a melhoria da qualidade do ensino é o maior desafio dos países, não só do Brasil. ${ }^{52}$

No trecho citado, observa-se o uso do discurso da ineficiência da escola, pois para Schleicher, o tempo de escolaridade des-

51 O GLOBO - ed. - 18/05/2009.

52 O GLOBO, p. 3, 18/05/2009. 
ses jovens não foi convertido em aprendizagem. Ao tentar entender as possíveis causas do sucesso de alguns países no PISA, o jornalista Demétrio Weber considera que:

Os professores nesses países conseguem dar conta das diferenças dos estudantes de modo muito construtivo: dão apoio aos mais fracos, sem deixar de incentivar as habilidades dos mais fortes. 53

Isto é, atribui toda responsabilidade aos professores e à maneira de eles lidarem com as diferenças. Ou seja, a qualidade é atribuída a esses países porque conseguem homogeneizar o desempenho dos estudantes a ponto de conseguirem expressar os mesmos níveis de conhecimentos sobre os temas abordados na prova.

Assim, como denuncia Ravitch (2013), é possível observar o uso do exame, no caso o PISA, para sustentar o argumento da crise na educação pública. Contrariando o discurso dos reformadores, ela afirma que "a educação pública não está quebrada. Não está falindo ou em declínio. O diagnóstico está errado, e as soluções dos reformadores empresariais estão erradas. Nossas escolas estão em apuros por causa da desigualdade social e segregação racial". ${ }^{54}$

Por trás do argumento da crise, os índices de desempenho assumem a função de justificar a criação de parcerias com empresas privadas e a compra de metodologias de ensino.

O discurso da crise da educação deve ser relativizado e questionado. Não pode ser justificativa para a adoção de medidas padronizadas e centralizadas que tentam retirar a autonomia dos docentes como se eles fossem os culpados da suposta crise. Apple; Beane (2001) alertam sobre a necessidade de se negar a escolher entre o conformismo e as iniciativas de livre mercado:

53 O GLOBO, p. 3, 18/05/2009.

54 RAVITCH, 2013, p. 4.
No meio dos ataques gerais à educação, temos de manter viva a longa tradição da reforma educacional democrática que desempenhou o papel importantíssimo de fazer de muitas escolas lugares cheios de vitalidade e força para aqueles que as frequentam. [...] Apesar das incansáveis tentativas de algumas pessoas de nos levar a pensar o contrário, não temos de nos resignar a escoIher entre um sistema decadente de escola pública e as iniciativas de mercado como projetos de escolas "públicas" que visam o lucro, administradas por empresas privadas. 55

Não obstante, isso não significa afirmar que a escola pública não precisa melhorar. É necessário valorizar as experiências democráticas e incluir os que estão excluídos. Com as atuais políticas educacionais regulatórias, essas experiências estão enfrentando cada vez mais resistências nas escolas, mas existem.

Além disso, é preciso dar atenção às questões estruturais. Os diagnósticos provenientes dos exames não consideram a falta de professores, baixos salários ou más condições de trabalho como importantes para a melhoria da escola pública. Apesar das questões estruturais que os docentes reivindicam, as redes de ensino investem milhões no mercado educacional, contratando empresas para criar e aplicar testes e comprando projetos de alfabetização e correção da distorção idade-série.

\section{CONSIDERAÇÕES FINAIS}

Os representantes dos reformadores não escondem a intenção de buscar protagonismo nas decisões da política educacional brasileira. Por meio dos documentos apresentados, buscou-se demonstrar os diagnósticos e ações que orientam esses sujeitos e instituições.

Por intermédio da organização em redes de influência, os reformadores fazem uso também de organizações sem fins lucrativos que falam em nome da sociedade civil, mas são fi-

55 APPLE; BEANE, 2001, p. 11. 
nanciadas pelo empresariado. Por isso, neste ponto, faz-se necessário retornar à pergunta presente no título: que educação querem os reformadores? Em outras palavras, qual é a educação de qualidade prezada por eles?

Ora, pode-se resumir afirmando que eles buscam uma escola pública eficiente, na qual o investimento público se traduza em competitividade para as empresas, em formação de reserva de mão de obra qualificada e em economia dos recursos atualmente investidos no treinamento para o trabalho. Além disso, a intensificação do mercado educacional, por meio da privatização, é vista com grande potencial, gerador de lucros e capaz de aumentar a influência nos contextos da escrita do texto político e da prática.

A partir do que foi pesquisado, faz-se possível afirmar que a avaliação externa tem desempenhado funções estratégicas nesse contexto. Fortalecendo o argumento a respeito da crise na educação pública para criar mecanismos de privatização; impondo a lógica da performatividade; e fortalecendo a cultura do exame nas escolas para tentar controlar os conteúdos e tempos escolares.

\section{REFERÊNCIAS}

APPLE, M.; BEANE, J. (Orgs.). Escolas Democráticas, 2. ed. São Paulo: Cortez, 2001.

BALL, S. J. Global Education inc.: policy networks and edu-business. Oxon: Routledge, 2012.

. Sociologia das políticas educacionais e pesquisa críticosocial: uma revisão pessoal das políticas educacionais e da pesquisa em política educacional. Currículo sem Fronteiras, v. 6, n. 2, p. 10-32, jul./dez. 2006.

. Profissionalismo, gerencialismo e performatividade. Cad. Pesqui. São Paulo: v. 35, n. 126, dez. 2005. Disponível em <http://www.scielo.br/scielo.php?script=sci_arttext\&pid=S0100-15742005000300002\&lng=pt\&nrm=iso>. Acessos em 18 ago. 2013. http://dx.doi.org/10.1590/ S0100-15742005000300002.

BOURDIEU, P. Escritos de Educação, 11. ed. Petrópolis, RJ: Vozes, 2010.

. Os usos sociais da ciência: por uma sociologia clínica do campo científico. São Paulo: Editora UNESP, 2004.

BOWE, R.; BALL, S.; GOLD, A. Reforming education \& changing schools: case studies in policy sociology. London: Routledge, 1992.

BRASIL. Decreto № 6.094, de 24 de abril de 2007. Diário Oficial [da] República Federativa do Brasil, Poder Executivo. Brasília, DF, 25 de abril de 2007, p. 5.

. Ministério da Educação. PDE: Prova Brasil - ensino fundamental: matrizes de referência, tópicos e descritores. Brasília: MEC, SEB; Inep, 2008. Disponível em: <http://portal.mec.gov. br/dmdocuments/prova\%2obrasil_matriz2.pdf > Acesso em: 11 nov. 2013.

BRASIL, MEC. Portaria NN. 867, de 4 de julho de 2012.

CNI. Mapa estratégico da indústria 2013-2022. Brasília: CNI, 2013.

DIAS SOBRINHO, J. Avaliação: políticas educacionais e reformas da educação superior. São Paulo: Cortez, 2003.

EVANGELISTA, O. LEHER, R. Todos pela Educação e o episódio Costin no MEC: a pedagogia do capital em ação na política educacional brasileira. Trabalho Necessário. Niterói: Ano 10, nº. 15, 2012. 
FERNANDES, C. O. A Escolaridade em Ciclos: práticas que conformam a escola dentro de uma nova lógica - a transição para a escola do século XXI. Tese de doutorado. Orientador: Francisco Creso Franco Junior. Pontifícia Universidade Católica do Rio de Janeiro, 2003.

FERNANDES, C. O.; NAZARETH, H. D. G. A retórica por uma educação de qualidade e a avaliação de larga escala. Revista Impulso, v. 21, n. 51, p. 63-71, jan./jun. 2011.

FREITAS, L. C. Os reformadores empresariais da educação: da desmoralização do magistério à destruição do sistema público de educação. Educ. Soc., v. 33, n. 119, p. 379-404, 2012.

. Os reformadores empresariais da educação: a consolidação do neotecnicismo no Brasil. In: FONTOURA, H. A. (Org.). Políticas públicas, movimentos sociais: desafios à Pós-graduação em Educação em suas múltiplas dimensões. Rio de Janeiro: ANPEd Nacional, p. 72-90, 2011a.

. Os reformadores empresariais da educação: a consolidação do neotecnicismo no Brasil. In: FONTOURA, H. A. (Org.). Políticas públicas, movimentos sociais: desafios à Pós-graduação em Educação em suas múltiplas dimensões. Rio de Janeiro: ANPEd Nacional, 2011b, p. 72-90.

GESQUI, L. C. O estreitamento curricular em função dos resultados das avaliações externas em larga escala. Práxis Educacional. Vitória da Conquista, v. 11, n. 20, p. 229-245, 2015.

GIROUX, H.; SIMON, R. Cultura popular e Pedagogia Crítica: a vida cotidiana como base para o conhecimento curricular. In: MOREIRA, A. F. \& SILVA, T. T. Currículo, cultura e sociedade, 11. ed. São Paulo: Cortez, 2009.

LIMA, I. G.; GANDIN, L. A. Entendendo o estado gerencial e sua relação com a educação: algumas ferramentas de análise. Práxis Educativa. Ponta Grossa, v. 7, n. 1, p. 69-84, jan./jun. 2012.

MAINARDES, J. Abordagem do ciclo de políticas: uma contribuição para a análise de políticas educacionais. Educ. Soc. Campinas, v. 27, n. 94, abr. 2006. Disponível em <http://www.scielo.br/ scielo.php?script=sci_arttext\&pid=S0101-73302006000100003\&lng=pt\&nrm=iso $>$. Acesso em 11 ago. 2013. http://dx.doi.org/10.1590/S0101-73302006000100003.

MARTINS, E. M. Redes sociais para educação: atuação do empresariado no contexto latinoamericano. In: 36 reunião anual da ANPEd, 2013. Goiânia. Disponível em:<http://www.36reuniao. anped.org.br/pdfs_posteres_aprovados/gt05_posteres_aprovados/gt05_3273_texto.pdf> acesso em 10 set. 2013.

MOREIRA, A. F.; KRAMER, S. Contemporaneidade, educação e tecnologia. Educ. Soc. Campinas, v. 28, n. 100, out. 2007. Disponível em <http://www.scielo.br/scielo.php?script=sci_ arttext\&pid=S0101- 3302007000300019\&Ing=en\&nrm=iso>. Acesso em 10 set. 2014.

OLIVEIRA, A. C. P. Política pública e Prática docente: quando e como dialogam no espaço escolar. Dissertação de mestrado. Orientadora: MARCONDES, Maria Inês. Pontifícia Universidade Católica do Rio de Janeiro. 2012.

RAVITCH, D. Reign of error: The Hoax of the Privatization Movement and the Danger to America's Public Schools. New York: Alfred A. Knopf, 2013.

REDUCA. Missão. Disponível em: <http://www.reduca-al.net>. Acesso em: 9 jan. 2015.

RICARDO FILHO, G. S. A boa escola no discurso da mídia. São Paulo: Editora UNESP, 2005.

RIO DE JANEIRO. Plano Estratégico da Prefeitura do Rio de Janeiro 2013-2016. Rio de Janeiro, 2013. Disponível em <http://www.rio.rj.gov.br/dlstatic/10112/2116763/4104304/planejamento_estrategico_1316.pdf> acesso em 9 dez. 2013. 
RIO DE JANEIRO, SME. Resolução Nº 1.178/2012.

RIO DE JANEIRO, SME. Resolução N. 2.640/2004.

RUGGERI, R. G. Gerenciamento de projetos no terceiro setor. Rio de Janeiro: Brasport, 2011.

SHIROMA, E. et al. Conversão das "almas" pela liturgia da palavra: uma análise do discurso do movimento Todos pela Educação. In: BALL, S. MAINARDES, J. (Orgs.). Políticas Educacionais: questões e dilemas. São Paulo: Cortez, 2011.

TODOS PELA EDUCAÇÃO. Quem somos. Disponível em: <http://www.todospelaeducacao.org. br/institucional/quem-somos/>. Acesso em: 16 set. 2013.

\section{DAdOS DO AUTOR}

\section{HeNRIQUe Dias Gomes de Nazareth}

Doutorando em Educação pela Universidade Federal do Estado do Rio de Janeiro. Professor tutor do curso semipresencial de Pedagogia da Universidade Federal do Estado do Rio de Janeiro. Rio de Janeiro/RJ - Brasil.h_diasunirio@yahoo.com.br

Submetido em: 25-07-2016

Aceito em: 26-04-2017 